\title{
Capsule endoscopy: Specifics for enhanced performance - Part II
}

\author{
Robert Enns MD
}

\begin{abstract}
Capsule endoscopy (CE) is a relatively new method that assesses the gastrointestinal tract via a wireless transmitter. Although there are capsules designed for the esophagus (1-4) and newer ones undergoing testing in the colon, CE is primarily used to investigate small intestinal disorders (5-9). In the August issue of The Canadian Journal of Gastroenterology, the primary indications for CE were outlined (10). Although we have numerous studies on CE, it must be recognized that the technology (particularly from a scientific medical research point of view) is still in its infancy, and recommendations may change from year to year.

Because there is limited reimbursement and availability for CE, the actual method by which one performs $\mathrm{CE}$ is critical to ensuring adequate images during the initial study, thereby limiting repeated studies. Because many patients may be travelling extensive distances (with considerable
\end{abstract} cost involved), assurance of an ideal study is critical before discharge. Although the data are limited and changing, there are studies available (of varying quality and design) that give some guidance on the actual performance of a CE study.

From a practical standpoint, the first issue with performing a $\mathrm{CE}$ is scheduling. There are a couple of key questions to ask when scheduling. First, can the patient actually swallow the capsule? Many referring physicians are only vaguely familiar with the actual performance of the study and swallowing issues may not be considered as a possible contraindication of the study. Patients with Zenker's diverticulum, esophageal motility disorders or strictures, and children younger than eight years of age must be considered for endoscopic capsule placement (which involves optical endoscopic scheduling) (11-16). Although a relatively easy procedure, endoscopic placement is performed in conjunction with activation of the capsule; therefore, the patient must already have the data recorder and leads applied appropriately. It is very disrupting to the patient and other staff if an urgent endoscopic capsule placement is required early in the morning, essentially causing adjustment in elective endoscopic procedures, because a swallowing issue was not anticipated.

There are a couple of other important patient groups to consider when it comes to scheduling. Patients who are inpatients at other institutions typically arrive by ambulance. Because the application of the data recorder, monitoring leads and ingestion of the capsule only requires a few minutes, we should simply have the same ambulance crew waiting for these patients to immediately transport them back. When the patients are transported back to the referring hospital (provided it is within $2 \mathrm{~h}$ travel), the test is completed at the referring hospital. The data recorder is subsequently returned via courier the following day. This ensures that an entire day of nursing care is not spent on simply observing CE patients while the capsule traverses the small intestine. The nursing supervisor on the ward at the referring institution is always personally contacted by phone before the CE to minimize confusion and to stress the importance and cost of the monitoring device for which the referring hospital is now responsible.

For patients who are inpatients and who are on high doses of narcotics, known motility disorders exist such as diabetic autonomic neuropathy, and an increased likelihood of indeterminate studies have been recognized $(17,18)$. The same holds true for patients in whom ambulation is poor. These studies can be incomplete because either the capsule does not reach the cecum or there is particulate matter that limits visibility. Although we perform CE on all these patient groups, precautions are taken to maximize the interpretation of these patients' studies. All of these patients receive a colonic preparation. Additionally, if the patient is recovering from a condition and it is anticipated that he/she will be more ambulatory in the near future, the CE study is delayed until a more appropriate time (usually after discharge from hospital and when the patient is more fully ambulatory). For those patients requiring inpatient studies, we encourage ambulation. For patients with a failed study, because the capsule did not reach the cecum or because there was excessive particulate matter, a full colonic preparation is used. For patients with suspected gastroparesis, it is anticipated that the addition of real-time CE to visualize the site of the capsule may be of benefit in the near future. This feature allows the attending physician to change the monitoring device to a real-time device at any time during the study to immediately determine visibility and site location. This feature will likely be used 90 min postingestion to ensure the capsule has passed through the pylorus. If not, urgent endoscopic insertion into the duodenum could theoretically be performed. Alternatively, at the end of the capsule battery life (approximately $8 \mathrm{~h}$ ), real-time CE could be used to ensure the capsule has reached the cecum.

For the standard CE patient, we do not routinely recommend a colonic preparation. This recommendation is based on a recent $\mathrm{CE}$ consensus meeting that reviewed the use of preparations, defined as agents given to cleanse the small 
intestine before a CE study. The consensus group met on two occasions (March and June 2006) and reviewed approximately 70 existing reports on the topic. It was recognized that many of these reports were of varying quality, with only a few prospective studies being performed. For this reason, the consensus panel also included abstracts. The comparison of individual studies is further hampered by the fact that there is no validated scoring system to assess the quality of the preparations. To date, nine randomized studies on preparations before CE have been performed (seven of them involving polyethylene glycol solutions and four with sodium phosphate), with six of them demonstrating improved bowel cleanliness with preparation (19-27). However, only three of them involved more than 100 patients (none in fully published form), and only one of the three studies demonstrated improved visibility with a bowel preparation. At present, because a bowel preparation has not definitively been demonstrated to improve visibility (and hence yield), it has not been routinely recommended by the 2006 consensus panel.

There is even less information on the use of prokinetics before CE. In theory, a prokinetic may enhance gastric emptying and accelerate small bowel transit, thereby increasing cecal intubation rates and decreasing the viewing time required by the attending physician. Several reports (28-31) (all in abstract form) have suggested that a single dose of tegaserod (6 mg) given $1 \mathrm{~h}$ before ingestion of the capsule improves small bowel examinations. Erythromycin and domperidone have been studied and neither appears to affect small bowel transit time of the capsule (32-34), whereas one nonrandomized study (35) with metoclopramide demonstrated improvement of small bowel examination without any significant side effects. Larger scale studies and full manuscript peer-reviewed publications are required before any of these agents can be routinely recommended.

We tend to perform CE studies only on weekdays, excluding Fridays. The capsule battery life varies, but is approximately $8 \mathrm{~h}$ (enough time for $85 \%$ of the capsules to reach the cecum). For this reason, all patients arrive at our site for their studies at 07:00. This ensures that they have ingested the capsule by 08:00 and that they return their data recorders by $17: 00$, thereby preventing overtime requirements by any nursing staff receiving and downloading the data recorder. With the newer versions of RAPID Reader (Given Imaging Inc, USA), the downloading time is only approximately $20 \mathrm{~min}$ and is therefore completed by the time the nursing staff leaves the clinic at 17:30.

Subsequently, I interpret the capsule studies the following morning. Because the entire study has been downloaded the previous evening, I am able to arrive early, before the nursing staff the following morning, read the study and notify the patient if the study is incomplete or inadequate. All studies are interpreted the following morning (therefore we do not perform CEs on Fridays), and direct calls are made to patients to instruct them on further management. For incomplete studies, we will occasionally perform another study within the next $24 \mathrm{~h}$ (particularly if the patient has travelled some distance to the site). This system ensures rapid performance of the study and direct communication with the patient, minimizing confusion in this specialized area. Some interested patients will return to the clinic the following morning and I (or our capsule nurse) will personally review the study and any abnormalities along with a suggested plan. This is highly beneficial because many patients (and physicians) are not experienced in management strategies once CE is completed.

For negative studies, a report is immediately sent to the referring physician with recommendations for management. Often this will involve simply monitoring the patient for further bleeding. Double balloon enteroscopy may be added in the near future in many tertiary centres, giving another option for patients with negative studies. It is recognized that some capsule studies are falsely negative for various reasons (including diminutive lesions that only bleed intermittently). In the future, for patients with negative capsules with ongoing bleeding (or perhaps even a high suspicion of a lesion), double balloon enteroscopy may be recommended.

For positive studies, our immediate management will depend on the site of bleeding. If a lesion is seen within endoscopic access of a standard gastroscope or push enteroscope in the upper gastrointestinal tract, I will often have the patient come immediately to the clinic for an urgent endoscopic assessment. If the bleeding appears to be distal to the mid-jejunum, the referring physician is notified and the patient is assessed urgently. Because approximately $10 \%$ of lesions we have found on $\mathrm{CE}$ are actually seen in the cecum, an urgent purge colonoscopy will occasionally be recommended; although, this is usually discussed and arranged through the referring physician. If the referring physician is unavailable, I will undertake the examination urgently. I believe that urgent assessment is critical in these patients because most of them have challenging lesions to locate, and once located, action should follow to maximize the therapeutic advantage.

At present, lesions seen in the small intestine which are out of reach of push enteroscopy are managed surgically This can be performed laparoscopically (for a mass lesion), although most small bowel bleeding approached surgically will require a midline incision. Although CE can give some direction as to the site of the lesion, this is approximate. It must always be possible to perform an intraoperative enteroscopy if the lesion cannot be located visually or manually by running the small intestine. Because of the complexity of the surgical assessment, these patients are always discussed directly with the referring physician the same day the capsule is interpreted (ie, the day after ingestion). A smooth line of communication is critical for patients and physicians because, if not, it is common for the patient to return to our clinic, months later, with the same presenting complaint and having had no definitive management.

The last issue to address is that of capsule excretion. Capsule retention is uncommon, but will occur at higher frequencies in patients being evaluated for small bowel strictures. The development of a new patency capsule will no doubt limit capsule impaction, but it is still something that may occasionally occur. All patients are consented for this complication. Most patients who develop capsule impaction do not develop symptoms of obstruction. The problem should be suspected in patients in whom the capsule does not reach the cecum. Often the capsule images demonstrate a single site in numerous different frames, indicating a transit abnormality. For all patients who do not visualize the capsule passing rectally over the next seven days, or in whom symptoms of obstruction are suspected, an abdominal radiograph is performed to ensure passage of the capsule. The requisitions are supplied to the patient at the time of ingestion of their capsule (because many of the patients are not returning back to the clinic). Usually the capsule has passed, and if not, a discussion with the patient regarding management 
will follow. This may include surgery for patients in whom the capsule has impacted at a site of definitive disease. Alternatively, an approach of watchful waiting (follow-up radiographs if the capsule is lodged in a presumed benign lesion such as a web or ring) or even medical management (in the setting of Crohn's strictures where therapy may decrease inflammation, allowing increased diameter of the narrowing and subsequent passage of the capsule).

\section{REFERENCES}

1. Lapalus MG, Dumortier J, Fumex F, et al. Esophageal capsule endoscopy versus esophagogastroduodenoscopy for evaluating portal hypertension: A prospective comparative study of performance and tolerance. Endoscopy 2006;38:36-41.

2, Ricer RE, Eisen GM, Rao G. When is esophageal capsule endoscopy appropriate? A panel discussion. J Fam Pract 2005;Suppl:19-20.

3. Sharma VK, Eliakim R, Sharma P, Faigel D; ICCE. ICCE consensus for esophageal capsule endoscopy. Endoscopy 2005;37:1060-4.

4. Eliakim R, Sharma VK, Yassin K, et al. A prospective study of the diagnostic accuracy of PillCam ESO esophageal capsule endoscopy versus conventional upper endoscopy in patients with chronic gastroesophageal reflux diseases. J Clin Gastroenterol 2005;39:572-8.

5. Appleyard M, Fireman Z, Glukhovsky A, et al. A randomized trial comparing wireless capsule endoscopy with push enteroscopy for the detection of small-bowel lesions. Gastroenterology 2000;119:1431-8

6. Bourreille A, Jarry M, D'Halluin PN, et al. Wireless capsule endoscopy versus ileocolonoscopy for the diagnosis of postoperative recurrence of Crohn's disease: A prospective study. Gut 2006;55:978-83.

7. Costamagna G, Shah SK, Riccioni ME, et al. A prospective trial comparing small bowel radiographs and video capsule endoscopy for suspected small bowel disease. Gastroenterology 2002;123:999-1005.

8. Eliakim R, Fischer D, Suissa A, et al. Wireless capsule video endoscopy is a superior diagnostic tool in comparison to barium follow-through and computerized tomography in patients with suspected Crohn's disease. Eur J Gastroenterol Hepatol 2003;15:363-7.

9. Lewis BS, Swain P. Capsule endoscopy in the evaluation of patients with suspected small intestinal bleeding: Results of a pilot study. Gastrointest Endosc 2002;56:349-53.

10. Enns R. Who would I consider for capsule endoscopy? - Part I. Can J Gastroenterol 2006;20:517-8.

11. Ford RM, Affronti J, Cohen R, Baumgarten DA, Cai Q. Zenker's diverticulum: A contraindication for wireless capsule endoscopy? J Clin Gastroenterol 2005;39:257.

12. Hollerbach S, Kraus K, Willert J, Schulmann K, Schmiegel W. Endoscopically assisted video capsule endoscopy of the small bowel in patients with functional gastric outlet obstruction. Endoscopy 2003;35:226-9.

13. Kavin H, Berman J, Martin TL, Feldman A, Forsey-Koukol K. Successful wireless capsule endoscopy for a 2.5-year-old child: Obscure gastrointestinal bleeding from mixed, juvenile, capillary hemangioma-angiomatosis of the jejunum. Pediatrics 2006;117:539-43

14. Quan C, Chen G, Lee-Henderson M, et al. Overtube-assisted placement of wireless capsule endoscopy device. Gastrointest Endosc 2005;61:914-6

15. Redondo-Cerezo E, Perez-Sola A, Gomez C, et al. Oesophageal entrapment of wireless capsule endoscopy in valvular patients. Gut 2005;54:309-10

16. Wong GL, Lai LH, Lau JY, Sung JJ, Leung WK. Prolonged esophageal transit during wireless capsule endoscopy: A series of five cases and analysis of risk factors. J Clin Gastroenterol 2006;40:176.

17. Ben-Soussan E, Savoye G, Antonietti M, Ramirez S, Lerebours E, Ducrotte P. Factors that affect gastric passage of video capsule. Gastrointest Endosc 2005;62:785-90.
In summary, the preparation of patients for $\mathrm{CE}$ is critical to maximize the visibility and extent of the study. At present, routine use of preparations and prokinetics may not be recommended, although specific patient subgroups should be targets for careful preparation. The careful preparation and selection of patients, in addition to the immediate management of positive results, will serve to maximize yields and thereby enhance patient care.

18. Chan S, Wang J, Daniels JM, Jutabha R, Lo S. A retrospective evaluation of wireless capsule endoscopy: Determination of factors that influence transit time. Gastrointest Endosc 2004;59:175. (Abst)

19. Andrews AH, Napierkowski J, Lake J, Maydonovitch C, Wong RK. Efficacy of bowel preparation in capsule endoscopy: A prospective, randomized single-blinded controlled study. Gastrointest Endosc 2005;128(4 Suppl 2):P210. (Abst)

20. Chong A, Miller A, Taylor A, Desmond P. Randomised controlled trial of polyethyelene glycol administration prior to capsule endoscopy. Gastrointest Endosc 2004;59:179. (Abst)

21. Kim YS, Chun HJ, Kim KO et al. Comparison of two bowel preparations for capsule endoscopy: NPO versus PEG. Gastrointest Endosc 2003;57:169. (Abst)

22. Lapalus M, Saurin J, Mion F, Ponchon T. Prospective randomized single-blind trial on oral sodium phosphate efficacy for small intestine preparation before capsule endoscopy. Endoscopy 2003;35(Suppl II):A183. (Abst)

23. Lapalus MG, Ben Soussan E, Saurin JC, et al. Capsule endoscopy and bowel preparation with oral sodium phosphate: A prospective randomized controlled trial. The 5th International Conference on Capsule Endoscopy. Paris, France, June 9 to 10, 2006.

24. Pons V, Gonzalez B, Gonzalez C, et al. Evaluation of different bowel preparations for the study with capsule endoscopy: A prospective, randomized, controlled study. Gastrointest Endosc 2006;63:161. (Abst)

25. Shiotani A, Opekun OR, Graham DY. Improved visualization of the small intestine using capsule endoscopy. Gastrointest Endosc 2005;61. (Abst)

26. Viazis N, Sgouros S, Papaxoinis K et al. Bowel preparation increases the diagnostic yield of capsule endoscopy: A prospective, randomized, controlled study. Gastrointest Endosc 2004;60:534-8.

27. Wi J, Moon J, Kim Y, et al. A prospective randomized multicenter study of preparation for capsule endoscopy. Digestive Disease Week 2006. Gastrointest Endosc 2006;63:168. (Abst)

28. Storch IM, Schmelkin I, Vance S, Barkin J. A double blind placebo controlled study of tegaserod to increase gastric and small bowel transit times with wireless capsule endoscopy (WCE): Preliminary data. Gastrointest Endosc 2006;63:AB192.

29. Schmelkin IJ. Tegaserod decreases small bowel transit times in patients undergoing capsule endoscopy. Gastrointest Endosc 2004;59:P176. (Abst)

30. Schmelkin IJ. Premedication with tegaserod decreases both gastric emptying time and small bowel transit time in patients undergoing capsule endoscopy. Am J Gastroenterol 2004;99:A947. (Abst)

31. Kim K, Kim S, Rho E. Tegaserod increases colonic entry rate in patients undergoing capsule endoscopy. Gastrointest Endosc 2005;61:M1349. (Abst)

32. Keuchel M, Voderholzer W, Schenk G, Csomos G, Hagenmuller F, Lochs $\mathrm{H}$. Domperidone shortens gastric transit time of video capsule endoscope. Endoscopy 2003;35(Suppl 2):A185. (Abst)

33. Leung WK, Chan FK, Fung SS, Wong MY, Sung JJ. Effect of oral erythromycin on gastric and small bowel transit time of capsule endoscopy. World J Gastroenterol 2005;11:4865-8.

34. Lee H, Condon D, Mineyama Y, Wallace D. Effect of erythromycin on transit time in video capsule endoscopy: A randomized prospective placebo controlled trial. Gastrointest Endosc 2006;63:AB159. (Abst)

35. Selby W. Complete small bowel transit in patients: Determining factors and improvement with metoclopramide. Gastrointest Endosc $2005 ; 61: 80-5$ 


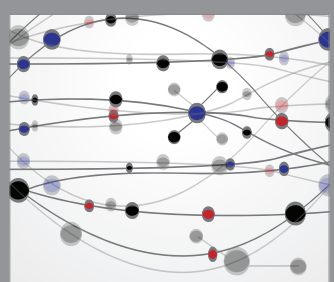

The Scientific World Journal
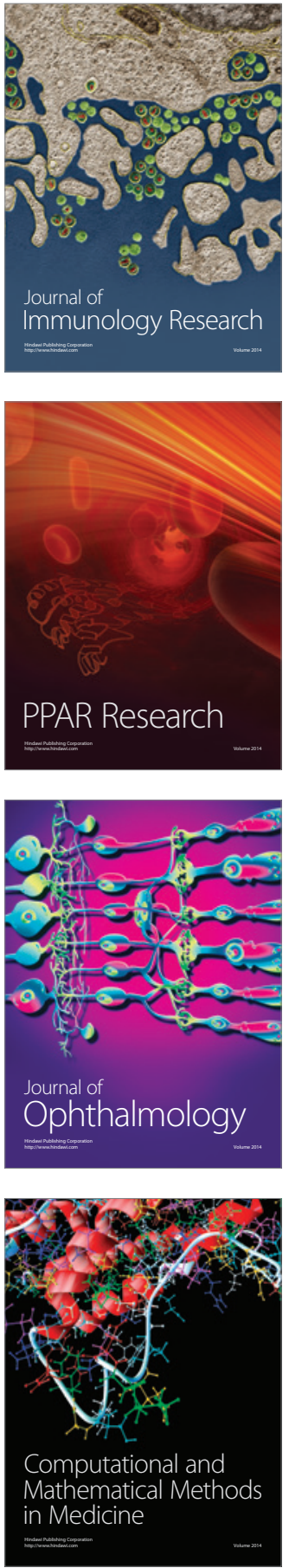

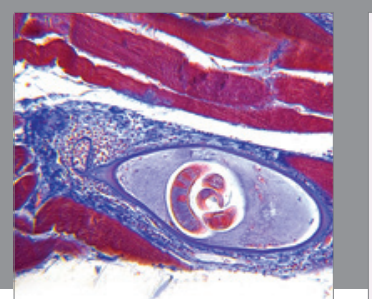

Gastroenterology Research and Practice

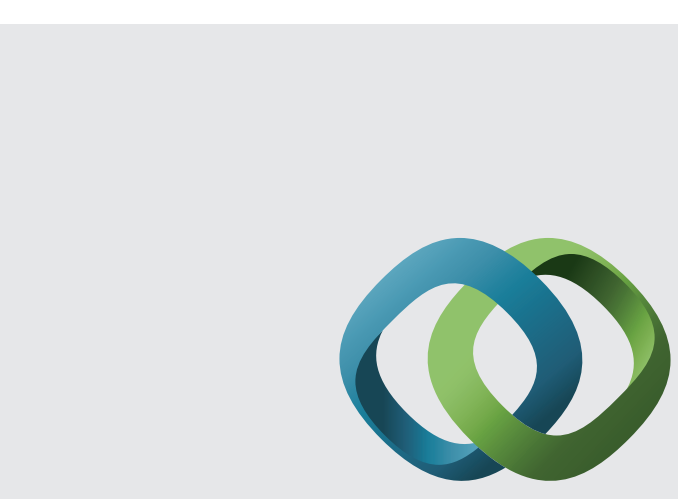

\section{Hindawi}

Submit your manuscripts at

http://www.hindawi.com
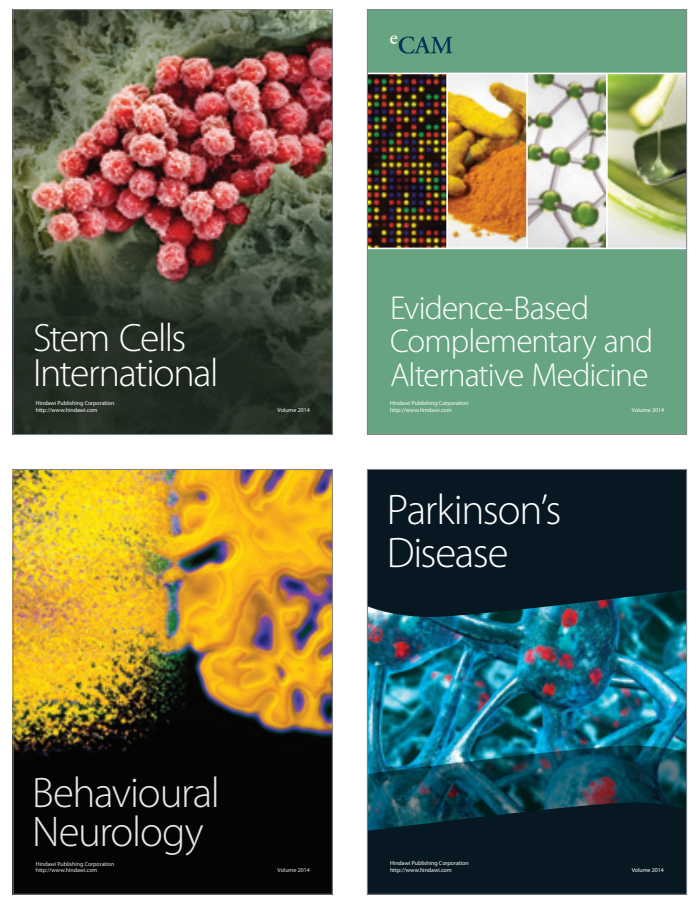
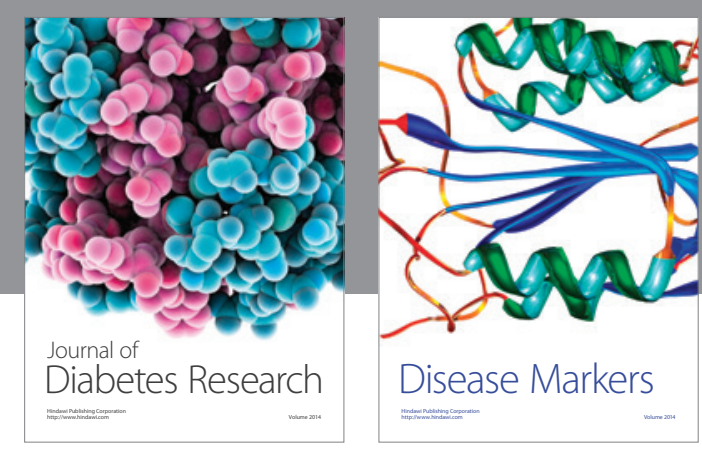

Disease Markers
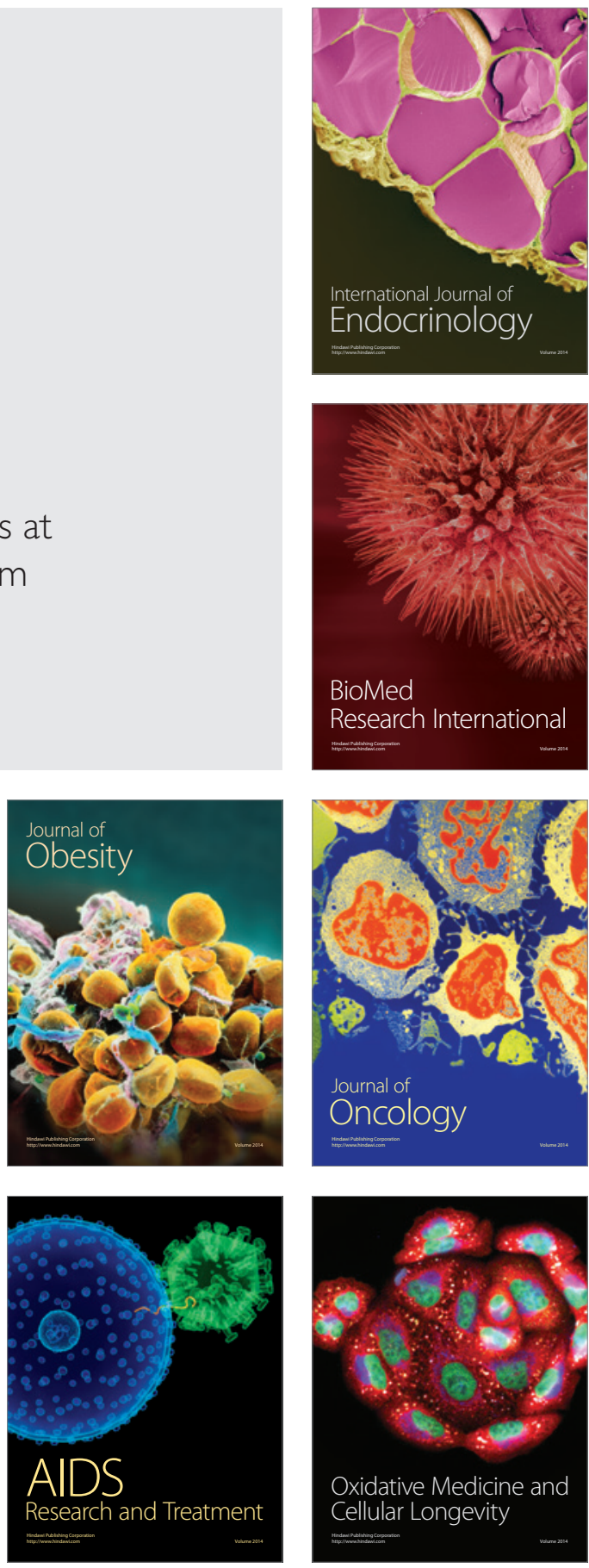